\title{
Preliminary screening of type IV secretion system in divergent geographic sources of Clostridium difficile
}

\author{
NA LI ${ }^{1}$, HONGBING JIA ${ }^{2}$, HUI YANG ${ }^{2}$, BING JI $^{1}$, YONGYUN LIU ${ }^{1}$, \\ XINGUO PENG ${ }^{1}$, YING CHENG ${ }^{3}$ and WEN ZHANG ${ }^{3}$
}

\begin{abstract}
${ }^{1}$ Department of Clinical Laboratory, The Affiliated Hospital of Binzhou Medical University, Binzhou, Shandong 256600; ${ }^{2}$ Department of Clinical Laboratory, China-Japan Friendship Hospital, Beijing 100029;

${ }^{3}$ Key Laboratory for Infectious Disease Prevention and Control, National Institute for Communicable Disease

Control and Prevention, Chinese Center for Disease Control and Prevention, Beijing 102206, P.R. China
\end{abstract}

Received September 27, 2016; Accepted June 15, 2017

DOI: $10.3892 /$ etm.2017.5065

\begin{abstract}
In the present study, different geographical sources and sequence types (STs) of Clostridium difficile were preliminarily screened to investigate the distribution profiles of three core genes, VirB4, VirB6 and VirD4, of the type IV secretion system (T4SS). A total of 37 C. difficile strains from different sources were screened, inoculated and prepared for genome extraction. $C$.difficile toxins $\mathrm{A}$ and $\mathrm{B}$ were subjected to identification and multilocus sequence typing (MLST) analysis. The T4SS gene then underwent polymerase chain reaction amplification and sequencing analysis. Of the 37 strains, 25 were toxin A- and toxin B-positive, and 12 were toxin A-negative and toxin B-positive. MLST detected 11 strains with ST37, 10 with ST2, 6 with ST35, 7 with ST3, 1 with ST54, 1 with ST1 and 1 with ST119. The detection rates of VirB4, VirB6 and VirD4 were all 100\% in colonies exhibiting T4SS. Single nucleotide polymorphisms (SNPs) were detected in a minority of strains. $C$. difficile strains with identical STs shared the same SNP loci for T4SS, and those with different STs had different SNP loci. The results of the present study may provide evidence for subsequent identification of T4SS distribution, epidemiological investigations, polymorphism analyses and research into the association between T4SS, cytotoxicity and enterotoxication in $C$. difficile.
\end{abstract}

Correspondence to: Dr Na Li, Department of Clinical Laboratory, The Affiliated Hospital of Binzhou Medical University, 661 Huanghe 2 Road, Binzhou, Shandong 256600, P.R. China

E-mail: bzyxylina@bzyxylina163.com

Dr Wen Zhang, Key Laboratory for Infectious Disease Prevention and Control, National Institute for Communicable Disease Control and Prevention, Chinese Center for Disease Control and Prevention, 155 Changbai Road, Changping, Beijing 102206, P.R. China

E-mail: doctorwen2016@sina.com

Key words: Clostridium difficile, sequencing type, type IV secretion system, multilocus sequence typing

\section{Introduction}

Clostridium difficile is a gram-positive anaerobic gemma bacillus that becomes well established in human colons, leading to diarrhea and inflammation in infected patients (1). It has been estimated that $30 \%$ of antibiotic-associated diarrhea and $90 \%$ of pseudomembranous enteritis result from $C$. difficile infection (CDI). CDI is prevalent around the globe; it has been reported that $€ 3.4$ billion is allocated to the diagnosis and treatment of CDI annually in the UK (1). In the United States, 300,000 cases of CDI are diagnosed every year, with an overall medical cost of $\$ 1.1$ billion (2). However, the pathogenesis and prevalence of CDI in China is poorly understood due to a lack of molecular and genetic data sources.

Pathogenic $C$. difficile strains produce multiple toxins $(1,2)$. The most well characterized are $C$. difficile toxins A and B, which may induce diarrhea and inflammatory diseases (3). These potent toxins have been the focus of various investigations $(2,3)$. However, the specific secretion procedures and relative contributions of $C$.difficile toxins $\mathrm{A}$ and $\mathrm{B}$ remain to be elucidated, and this information is important to determine the mechanism underlying CDI $(3,4)$. In a previous study by the present group (5), the existence of the type IV secretion system (T4SS) in $C$. difficile was identified, and was revealed to be potentially associated with the virulence of $C$. difficile. T4SS is a secretion system that is associated with the bacteria-binding mechanism (4). It is capable of transferring toxins or proteins to the host cells by forming an injector connecting to extracellular structures, directly leading to infectious diseases (6). T4SS is associated with the virulence of Helicobacter pylori, Bordetella pertussis, Legionella pneumophila, Coxiella burnetii, Escherichia coli and Bartonella (6-9). The T4SS was previously identified in the genome-wide sequencing of multiple $C$. difficile strains (9). However, the distribution of T4SS in $C$. difficile colonies is poorly understood due to a lack of epidemiological and experimental data. In the present study, different sources and sequencing types of $C$. difficile were preliminarily screened to investigate the distribution profiles of three core genes of T4SS, including VirB4 $\mathrm{m}$ VirB6 and VirD4, in $C$. difficile colonies. The aim of the present study was to provide evidence 
for elucidating and establishing the molecular polymorphism that results in T4SS in $C$. difficile.

\section{Materials and methods}

\section{Materials}

Sampling source. A total of 37 C. difficile strains of different sources were obtained from patients treated at the Department of Infectious diseases of different hospitals, 33 of which were verified for subsequent experiment. Written informed consent was obtained from all patients for inclusion in the present study. One strain, BJ08, was isolated in Beijing (Department of Clinical Laboratory, China-Japan Friendship Hospital; Beijing, China), 13 were isolated in Guangdong Institute of Microbiology in Guangzhou in the 1980s, 13 were isolated in Shanghai Institute of Microbiology (Shanghai, China) between 2007 and 2011, 6 in Shandong Institute of Microbiology (Jinan, China) between 2010 and 2012, 2 strains (UK1 and US1) were donated by Dr Feng Hanping from University of Maryland in the United States, and ATCC9689 and CD630 strains were purchased from the American Type Culture Collection (Manassas, VA, USA).

Reagents and instruments. Cycloserine-cefoxitin-fructose-egg yolk agar substrate and additive (CCFA) medium, brain heart infusion (BHI) agar, egg yolk emulsion and a BioMerieux kit were supplied by Oxoid (Thermo Fisher Scientific, Inc., Waltham, MA, USA). Proline paper was supplied by Remel, Inc. (San Diego, CA, USA), goat blood was obtained from Beijing Laboratory Biology Technology Co., Ltd (Beijing, China) and bacterial genomic DNA was purified from bacterial cultures using a QIAamp DNA extraction mini kit (Qiagen, Inc., Valencia, CA, USA) strictly according to the manufacturer's instructions. Polymerase chain reaction (PCR) primers and product sequences were provided by Shanghai Sangon Biotech Co., Ltd. (Shanghai, China), DNA polymerase was from Toyobo Co., Ltd. (Osaka, Japan) and markers were obtained from Takara Bio, Inc. (Otsu, Japan).

Bacterial culture and genome extraction. C. difficile strains of different sources were inoculated in CCFA culture medium in an anaerobic environment at $37^{\circ} \mathrm{C}$ for $48 \mathrm{~h}$. Single flat, yellow ground-glass like colonies with a horse dung smell and gram-positive bacillus were selected and inoculated in $\mathrm{BHI}$ culture medium under anaerobic conditions at $37^{\circ} \mathrm{C}$ for $24 \mathrm{~h}$. All cultured strains were verified strictly according to the manufacturers' instructions (REF203001; apiR20A system, BioMerieux, Inc., St. Louis, MO, USA). The verified strains were inoculated on a BHI blood disk in a streak pattern at $37^{\circ} \mathrm{C}$ for $48 \mathrm{~h}$. The genomic DNA of 37 strains was analyzed using a DP320 bacterial genomic DNA extraction kit (DP320; Qiagen GmbH; Hilden Germany), dissolved in Tris-EDTA buffer solution and stored at $-20^{\circ} \mathrm{C}$ for subsequent use. The present study was approved by the Ethics Committee of The Affiliated Hospital of Binzhou Medical University (Binzhou, China).

Identification and multilocus sequence typing (MLST) of toxins $A$ and $B$. The tcdA gene, which encodes enterotoxin A (9), was amplified according to the protocol described by Lemme et al (10). The tcdB gene, which encodes cytotoxin
B, was amplified according to the protocol described by Kato et al (11). The products were cultured on $1 \%$ agarose gel at $37^{\circ} \mathrm{C}$ for $24 \mathrm{~h}$, subjected to $100 \mathrm{~V}$ electrophoresis for 20-30 min and finally observed using a gel imaging system (ChemiDoc MP Imaging System; Bio-Rad Laboratories, Inc., Hercules, CA, USA) to verify the expression of toxins A and B. According to the protocol by Griffiths et al (12), 7 housekeeping genes including adenosine kinase, ATP synthase subunit alpha, 1-deoxy-D-xylulose 5-phosphate reductoisomerase, serine hydroxymethyltransferase, $r e c A$, superoxide dismutase and triosephosphateisomerase were subject to PCR amplification as follows: $94^{\circ} \mathrm{C}$ for $5 \mathrm{~min}, 94^{\circ} \mathrm{C}$ for $30 \mathrm{sec}, 53^{\circ} \mathrm{C}$ for $30 \mathrm{sec}$, $72^{\circ} \mathrm{C}$ for $30 \mathrm{sec}$ for 35 cycles and $72^{\circ} \mathrm{C}$ for $10 \mathrm{~min}$. DNA polymerase (20-80 ng/ $\mu \mathrm{l} ; 3 \mu \mathrm{l})$ was used (Takara Bio, Inc.). DNA sample was collected from the strains. The amplified products were delivered for sequencing (Shanghai Bioengineering Co., Ltd., Shanghai, China) and analyzed using Chromas software (Applied Biosystems; Thermo Fisher Scientific, Inc.). The sequence obtained was subsequently submitted to a database (http://pubmlst.org/cdifficile). The allele of toxins A and B was obtained and sequence typing of strains was verified, as illustrated in Table I.

PCR amplification and sequencing of T4SS gene. T4SS was detected in the $C$. difficile 630 strain containing three core genes; VirB4, VirB6 and VirD4. DNA sample was collected from the strains. DNA polymerase $(20-80 \mathrm{ng} / \mu \mathrm{l} ; 3 \mu \mathrm{l})$ was used (Takara Bio, Inc.). In the present study, the sequences of VirB4, VirB6 and VirD4 in C. difficile 630 were used as templates. To avoid false-positive or false-negative results, three pairs of primers were designed for each core gene, as illustrated in Table II.

The PCR reaction system $(30 \mu \mathrm{l})$ underwent 35 cycles of $95^{\circ} \mathrm{C}$ for $3 \mathrm{~min}, 94^{\circ} \mathrm{C}$ for $30 \mathrm{sec}, 55^{\circ} \mathrm{C}$ for $30 \mathrm{sec}, 72^{\circ} \mathrm{C}$ for $120 \mathrm{sec}$, and extension at $72^{\circ} \mathrm{C}$ for $7 \mathrm{~min}$. PCR products were subject to $1.5 \%$ agarose gel electrophoresis and positive results were verified for sequencing. The sequencing results were analyzed using Segman version 7.1 software (Beijing Genomics Institute, Beijing, China).

\section{Results}

PCR analysis. Of the 37 strains, 25 (67.6\%) were identified to be positive for toxin A and toxin B. The remaining 12 (32.4\%) were negative for toxin A and positive for toxin B. MLST detected 7 types of stains including 11 strains with sequence type (ST) 37, 10 strains with ST2, 6 strains with ST35, 7 strains with ST3, 1 strain with ST54, 1 strain with ST1 and 1 strain with ST119, respectively (Table III).

PCR outcomes of VirB4, VirB6 and VirD4 of 37 strains are presented in Fig. 1. Strains of the same ST shared similar outcomes. Positive results were observed in three core genes of 11 ST37 strains and 7 ST3 strains. A positive result was also noted in ST119 strains. Negative outcomes were observed in 3 core genes of the ATCC9689 strain, however positive results were detected in the other 3 standard strains. A total of 10 ST2 stains were observed to be weakly positive and 3 core genes of 6 ST35 stains were positive. However, double bands located at the target gene and at 2,000 bp were noted in the VirD4-F2R2 strain. This requires further verification in subsequent 
Table I. Toxins A and B primer and MLST of 7 housekeeping genes.

\begin{tabular}{|c|c|c|c|c|}
\hline Toxin & Gene & Direction & Sequence $\left(5^{\prime}-3^{\prime}\right)$ & Fragment size (bp) \\
\hline \multirow[t]{2}{*}{$\operatorname{tcd} A$} & $t c d A$ & $\mathrm{~F}$ & AGATTCCTATATTTACATGACAATAT & 369 \\
\hline & & $\mathrm{R}$ & GTATCAGGCATAAAGTAATATA CTTT & \\
\hline \multirow[t]{4}{*}{ tcdB } & NK104 & $\mathrm{F}$ & GTGTAGCAATGAAAGTCCAAGTTTACGC & 204 \\
\hline & NK105 & $\mathrm{R}$ & CACTTAGCTCTTTGATTGCTGCACCT & \\
\hline & $A d k$ & $\mathrm{~F}$ & TTACTTGGACCTCCAGGTGC & 635 \\
\hline & & $\mathrm{R}$ & TTTCCACTTCCTAAGGCTGC & \\
\hline \multirow[t]{12}{*}{ MSLT } & $\operatorname{atp} A$ & $\mathrm{~F}$ & TGATGATTTAAGTAAACAAGCTG & 674 \\
\hline & & $\mathrm{R}$ & AATCATGAGTGAAGTCTTCTCC & \\
\hline & $d x r$ & $\mathrm{~F}$ & GCTACTTTCCATTCTATCTG & 525 \\
\hline & & $\mathrm{R}$ & CCAACTCTTTGTGCTATAAA & \\
\hline & $\operatorname{gly} A$ & $\mathrm{~F}$ & ATAGCTGATGAGGTTGGAGC & 625 \\
\hline & & $\mathrm{R}$ & TTCTAGCCTTAGATTCTTCATC & \\
\hline & recA & $\mathrm{F}$ & CAGTAATGAAATTGGGAGAAGC & 705 \\
\hline & & $\mathrm{R}$ & ATTCAGCTTGCTTAAATGGTG & \\
\hline & $\operatorname{sodA}$ & $\mathrm{F}$ & CCAGTTGTCAATGTATTCATTTC & 585 \\
\hline & & $\mathrm{R}$ & ATAACTTCATTTGCTTTTACACC & \\
\hline & tpi & $\mathrm{F}$ & ATGAGAAAACCTATAATTGCAG & 640 \\
\hline & & $\mathrm{R}$ & TTGAAGGTTTAACACTTCCACC & \\
\hline
\end{tabular}

tcd, Clostridium difficile toxin; F, forward; R, reverse; Adk, adenosine kinase; MSLT, multilocus sequence typing; atpA, ATP synthase subunit alpha; $d x r$, 1-deoxy-D-xylulose 5-phosphate reductoisomerase; glyA, serine hydroxymethyltransferase; soda , superoxide dismutase; tpi, triosephosphate isomerase.

Table II. Primer sequences of three core genes of T4SS.

\begin{tabular}{|c|c|c|c|c|}
\hline Gene & Primer & Direction & Sequence $\left(5^{\prime}-3^{\prime}\right)$ & Fragment size (bp) \\
\hline \multirow[t]{6}{*}{ VirB6 } & \multirow[t]{2}{*}{ Primer 1} & $\mathrm{~F}$ & CTACTGGGCGGTATTCAAGC & \multirow[t]{2}{*}{288} \\
\hline & & $\mathrm{R}$ & CCATACAGCAATCCACATCTTG & \\
\hline & \multirow[t]{2}{*}{ Primer 2} & $\mathrm{~F}$ & GGAGAGCTTGTCATGATACTCTTTG & \multirow[t]{2}{*}{317} \\
\hline & & $\mathrm{R}$ & ACCGCATATCCAAGTATCGT & \\
\hline & \multirow[t]{2}{*}{ Primer 3} & $\mathrm{~F}$ & GATGTGGATTGCTGTATGGTT & \multirow[t]{2}{*}{304} \\
\hline & & $\mathrm{R}$ & TGGAATGGCTGAAATGGATG & \\
\hline \multirow[t]{6}{*}{ VirB4 } & \multirow[t]{2}{*}{ Primer 1} & $\mathrm{~F}$ & CGGTAGAAGATACCATTCCCT & \multirow[t]{2}{*}{257} \\
\hline & & $\mathrm{R}$ & TTTATCCGGTATCTGAATTGCC & \\
\hline & \multirow[t]{2}{*}{ Primer 2} & $\mathrm{~F}$ & GCGGATAATTTAGAACAGGCA & \multirow[t]{2}{*}{442} \\
\hline & & $\mathrm{R}$ & CCGATGGAAGAATGTCCATA & \\
\hline & \multirow[t]{2}{*}{ Primer 3} & $\mathrm{~F}$ & CCATTTACCACAGAGGAGCTTT & \multirow[t]{2}{*}{359} \\
\hline & & $\mathrm{R}$ & CTACCGCCTACTACAAGCTCAA & \\
\hline \multirow[t]{6}{*}{ VirD4 } & \multirow[t]{2}{*}{ Primer 1} & $\mathrm{~F}$ & GAGTATGGCTCGGCAAGATG & \multirow[t]{2}{*}{431} \\
\hline & & $\mathrm{R}$ & GCTTTTTCTCССТСТССТTTAG & \\
\hline & \multirow[t]{2}{*}{ Primer 2} & $\mathrm{~F}$ & TGCAAGATAAGGCAAAGTTTC & \multirow[t]{2}{*}{760} \\
\hline & & $\mathrm{R}$ & ACTTCTGAAGCGTCTATCATATC & \\
\hline & \multirow[t]{2}{*}{ Primer 3} & $\mathrm{~F}$ & TCTTGCTAACGCAAACAGAAC & \multirow[t]{2}{*}{1,300} \\
\hline & & $\mathrm{R}$ & AGTCCTCAAGGAGCTTGTAAT & \\
\hline
\end{tabular}

F, forward; R, reverse.

studies analyzing T4SS function. Based on the preliminary PCR outcomes, 14 representative strains of different sources and ST were selected for repeat PCR analysis. VirB4-F1R1,
VirB6-F2R2 and VirD4-F1R1 primers with the highest positive rate were chosen for subsequent PCR. Following one cycle of PCR analysis, the results of 7 strains including ST6 
Table III. Polymerase chain reaction results of multilocus sequence typing of VirB4, VirB6 and VirD4 of 37 strains of Clostridium difficile.

\begin{tabular}{|c|c|c|c|c|c|c|c|c|c|c|c|c|}
\hline \multirow[b]{2}{*}{ No. } & \multirow[b]{2}{*}{ Strain } & \multirow{2}{*}{$\begin{array}{c}\text { Toxin } \\
\text { genotyping }\end{array}$} & \multirow[b]{2}{*}{ ST } & \multicolumn{3}{|c|}{ VirB4 } & \multicolumn{3}{|c|}{ VirB6 } & \multicolumn{3}{|c|}{ VirD4 } \\
\hline & & & & F1R1 & F2R2 & F3R3 & F1R1 & F2R2 & F3R3 & F1R1 & F2R 2 & F3R3 \\
\hline 1 & CD630 & $\mathrm{A}+\mathrm{B}+$ & 54 & + & + & + & + & + & + & + & + & + \\
\hline 2 & UK1 & $\mathrm{A}+\mathrm{B}+$ & 1 & + & + & + & + & + & + & + & + & - \\
\hline 3 & ATCC9689 & $\mathrm{A}+\mathrm{B}+$ & 3 & - & - & - & - & - & - & - & - & - \\
\hline 4 & BJ08 & A-B+ & 37 & + & + & + & + & + & + & + & + & - \\
\hline 5 & US1 & A-B+ & 37 & + & + & + & + & + & + & + & + & + \\
\hline 6 & GZ15 & A-B+ & 119 & $+^{\mathrm{a}}$ & + & + & - & $+^{\mathrm{a}}$ & + & $+^{\mathrm{a}}$ & + & + \\
\hline 7 & GZ1 & $\mathrm{A}+\mathrm{B}+$ & 35 & + & + & + & + & - & + & + & - & - \\
\hline 8 & GZ2 & A-B+ & 37 & + & + & + & + & + & + & + & + & + \\
\hline 9 & GZ3 & A-B+ & 37 & $t^{\mathrm{a}}$ & + & + & + & $t^{\mathrm{a}}$ & + & $t^{\mathrm{a}}$ & + & + \\
\hline 10 & GZ5 & $\mathrm{A}+\mathrm{B}+$ & 2 & $-1+^{b}$ & - & $-/+$ & $-/+$ & $-1+^{b}$ & - & $-1+^{\mathrm{b}}$ & $-/+$ & $-/+$ \\
\hline 11 & GZ6 & A-B+ & 37 & $+^{\mathrm{a}}$ & + & + & + & $t^{\mathrm{a}}$ & + & $+^{\mathrm{a}}$ & + & + \\
\hline 12 & GZ7 & $\mathrm{A}+\mathrm{B}+$ & 2 & $-/+$ & - & $-/+$ & + & + & $-/+$ & $-/+$ & $-/+$ & - \\
\hline 13 & GZ8 & A-B+ & 37 & + & + & + & + & + & + & + & + & + \\
\hline 14 & GZ9 & A-B+ & 37 & + & + & + & + & + & + & + & + & + \\
\hline 15 & GZ11 & A-B+ & 37 & + & + & + & + & + & + & + & + & + \\
\hline 16 & GZ12 & A-B+ & 37 & + & + & + & + & + & + & + & + & + \\
\hline 17 & GZ13 & A-B+ & 37 & + & + & + & + & + & + & + & + & + \\
\hline 18 & GZ14 & A-B+ & 37 & + & + & + & + & + & + & + & + & + \\
\hline 19 & SH1 & $\mathrm{A}+\mathrm{B}+$ & 35 & $+^{\mathrm{a}}$ & + & + & + & $+^{\mathrm{a}}$ & + & $+^{\mathrm{a}}$ & $+^{\mathrm{c}}$ & - \\
\hline 20 & SH2 & $\mathrm{A}+\mathrm{B}+$ & 35 & $t^{\mathrm{a}}$ & + & + & + & $t^{\mathrm{a}}$ & + & $t^{\mathrm{a}}$ & $t^{\mathrm{c}}$ & - \\
\hline 21 & SH3 & $\mathrm{A}+\mathrm{B}+$ & 2 & $-/+$ & $-/+$ & $-/+$ & - & $-/+$ & $-/+$ & $-/+$ & $-/+$ & - \\
\hline 22 & SH4 & $\mathrm{A}+\mathrm{B}+$ & 2 & $-/+^{b}$ & $-/+$ & $-/+$ & - & $-/+^{b}$ & $-/+$ & $-/+^{b}$ & $-/+$ & - \\
\hline 23 & SH6 & $\mathrm{A}+\mathrm{B}+$ & 2 & $-/+$ & $-/+$ & - & - & $-/+$ & $-/+$ & - & $-/+$ & - \\
\hline 24 & SH7 & $\mathrm{A}+\mathrm{B}+$ & 2 & $-/+$ & $-/+$ & - & - & $-/+$ & $-/+$ & - & $-/+$ & - \\
\hline 25 & SH8 & $\mathrm{A}+\mathrm{B}+$ & 2 & $-/+$ & $-/+$ & - & - & $-/+$ & $-/+$ & $-/+$ & $-/+$ & - \\
\hline 26 & SH9 & $\mathrm{A}+\mathrm{B}+$ & 2 & $-/+$ & $-/+$ & - & - & $-/+$ & $-/+$ & $-/+$ & $-/+$ & - \\
\hline 27 & SH10 & $\mathrm{A}+\mathrm{B}+$ & 35 & + & + & + & + & + & + & + & $t^{\mathrm{c}}$ & - \\
\hline 28 & SH11 & $\mathrm{A}+\mathrm{B}+$ & 35 & + & + & + & + & + & + & + & $+^{c}$ & - \\
\hline 29 & SH12 & $\mathrm{A}+\mathrm{B}+$ & 35 & + & + & + & + & + & + & + & $+^{c}$ & - \\
\hline 30 & SH13 & $\mathrm{A}+\mathrm{B}+$ & 2 & $-/+$ & $-/+$ & - & - & $-/+$ & $-/+$ & $-/+$ & - & - \\
\hline 31 & SH14 & $\mathrm{A}+\mathrm{B}+$ & 2 & $-/+$ & $-/+$ & - & - & $-/+$ & $-/+$ & $-/+$ & - & - \\
\hline 32 & JN09 & $\mathrm{A}+\mathrm{B}+$ & 3 & + & + & + & + & + & + & + & + & + \\
\hline 33 & JN012 & $\mathrm{A}+\mathrm{B}+$ & 3 & + & + & + & + & + & + & + & + & + \\
\hline 34 & JN31 & $\mathrm{A}+\mathrm{B}+$ & 3 & + & + & + & + & + & + & + & + & + \\
\hline 35 & JN33 & $\mathrm{A}+\mathrm{B}+$ & 3 & + & + & + & + & + & + & + & + & + \\
\hline 36 & JN43 & $\mathrm{A}+\mathrm{B}+$ & 3 & $+^{\mathrm{a}}$ & + & + & + & $t^{\mathrm{a}}$ & + & $+^{\mathrm{a}}$ & + & + \\
\hline 37 & JN159 & $\mathrm{A}+\mathrm{B}+$ & 3 & $t^{\mathrm{a}}$ & + & + & + & $t^{\mathrm{a}}$ & + & $t^{\mathrm{a}}$ & + & + \\
\hline
\end{tabular}

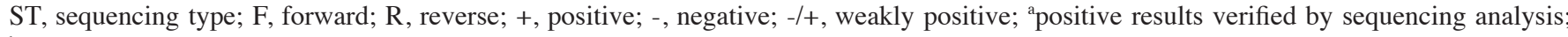
${ }^{\mathrm{b}}$ weakly positive outcome obtained after the first polymerase chain reaction and verified as positive after the second polymerase chain reaction; ${ }^{c}$ two bands with one located at the target gene and another band at 2,000 bp.

(GZ15), ST9 (GZ3), ST11 (GZ6), ST19 (SH1), ST20 (SH2), ST36 (JN43) and ST37 (JN159) were selected for sequencing. Following a second PCR analysis, the results of ST10 (GZ5) and ST22 (SH4) strains were chosen for sequencing analysis.

Sequencing analysis. The PCR results of 9 strains were sequenced and matched with the T4SS sequence verified by Segman software. SNPs were detected in a minority of strains. MLST revealed SNPs in 11 ST37 strains, 10 ST2 strains, 6 ST35 strains, 7 ST3 strains, 1 ST54 strain, 1
ST1 strain and 1 ST119 strain. Among 37 strains, 25 were positive for toxins $\mathrm{A}$ and $\mathrm{B}$ and 12 were negative for $\mathrm{A}$ and positive for B. The genome sequence of ATCC9689 strain was retrieved from the link below. (http://www.ncbi.nlm.nih. gov/nuccore/484228681? report=fasta). The Gene Prediction System For Type IV Secretion Systems (http://www.secretion. org/navigateT4SP.action) invented by our study group, was used and T4SS was not detected in the ATCC9689 strain, which was consistent with the PCR results. However, T4SS was detected in another 3 standard strains. Considering 

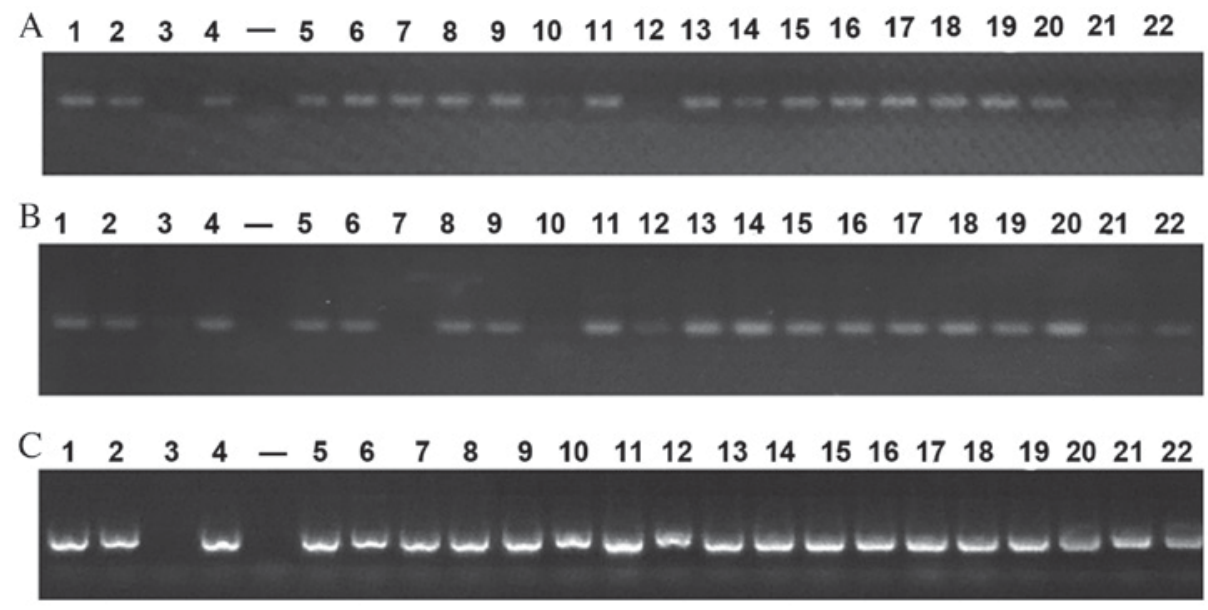

Figure 1. Polymerase chain reaction results for (A) VirB4-F1R1, (B) VirB6-F2R2 and (C) VirD4-F1R1.

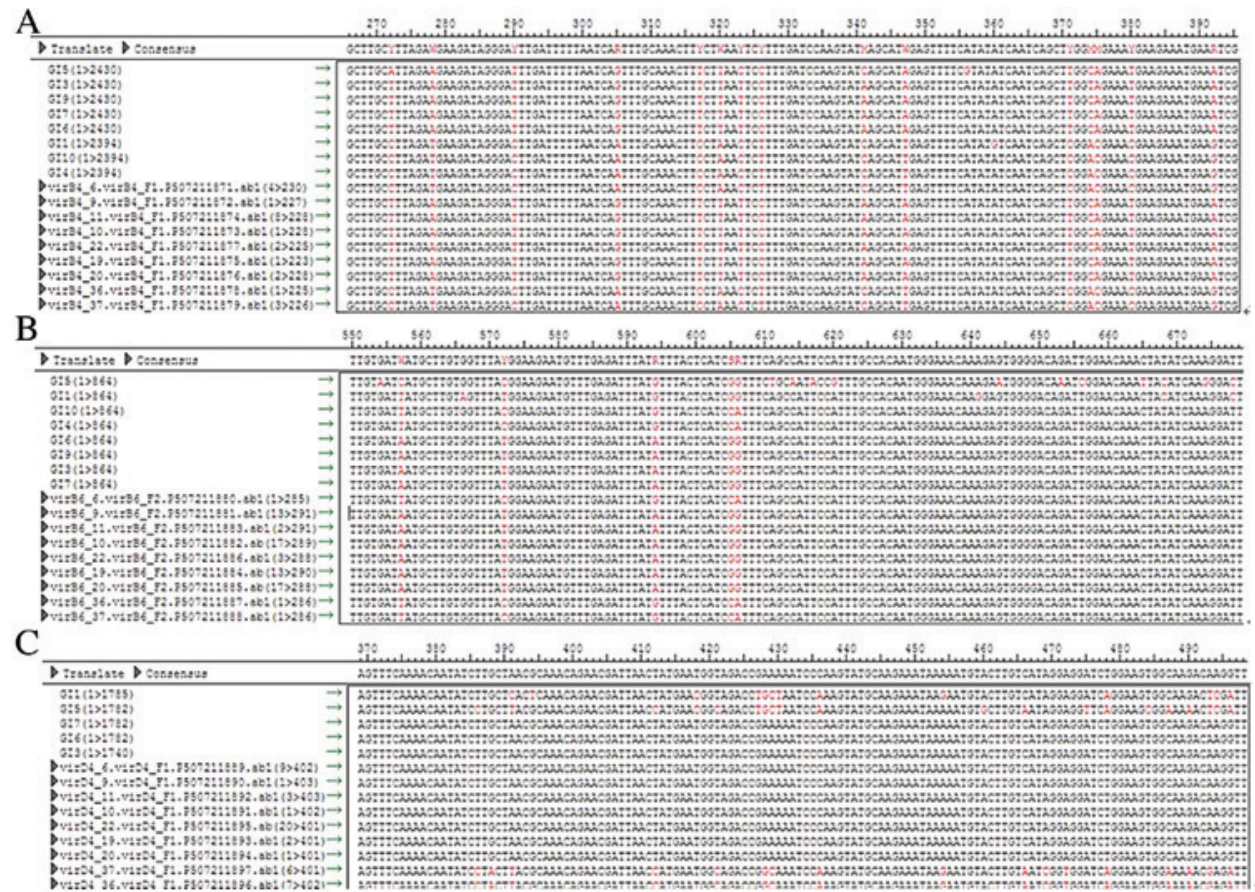

Figure 2. Polymerase chain reaction sequencing of (A) VirB4 (B) VirB6 and (C) VirD4 strains with different sequencing types.

varying geographic and ST factors, 9 strains of 3 regions and 5 STs were selected for PCR sequencing. The positive rate of T4SS was up to $100 \%$.

The VirB4, VirB6 and VirD4 sequences of ST2, ST37 and ST35 were observed to be identical. Strains with identical ST shared the same SNP loci of T4SS, whereas these loci differed in strains with different ST. This suggests that there is heredity disparity of T4SS in strains with different ST, as illustrated in Fig. 2.

\section{Discussion}

Previous studies have demonstrated that it is difficult to identify multiple strains of $C$. difficile (11-13), and researchers from the present study group have previously conducted fundamental studies on $C$. difficile (13). The gene polymorphism of toxins $\mathrm{A}$ and $\mathrm{B}$ of $C$. difficile has previously been studied in a clinical setting, as have the gene polymorphism and evolutionary characteristics of toxin A-negative and toxin B-positive $C$. difficile (13).

The genetic function, synthetic mechanism, receptor factors and evolution of toxins A and B have previously been intensively investigated (11-13). Nevertheless, how these toxins are transmitted from $C$. difficile to the outside environment remains poorly understood. Govind and Dupuy (14) initially proposed that toxins A and B may be transmitted to the external environment through $C$. difficile toxin $\mathrm{E}$ (TcdE) protein. However, TcdE deactivation in C. difficile 630 failed to alter the secretion levels of toxins A and B (15). The specific underlying mechanism of toxin secretion in $C$. difficile remains of interest in the medical field. In 2013, Brouwer et al (16) demonstrated that the pathogenicity locus of $C$. difficile 630 is capable of horizontally transferring toxigenic genes via a conjugation-like mechanism to non-toxigenic strains, which 
results in its conversion to a toxin producer. This study suggested that non-toxigenic strains may be a promising therapy for $C$. difficile-associated diarrhea (16).

T4SS is a secretion system associated with the mechanism underlying bacterial binding (17). It directly transports toxigenic proteins, but also mediates transportation at the genetic level via bacterial binding, transmits toxigenic genes, enhances pathogen virulence and contributes to bacterial evolution (17-20). In previous studies, a novel subtype of T4SS known as the type IVC secretion system has been observed $(17,20)$. In porcine streptococcus, type IVC has been demonstrated to mediate the horizontal transferring of 1 pathogenesis island of $89 \mathrm{~K}$ (4). As three core genes of T4SS subtype, VirB4, VirB6 and VirD4 serve synergistic effects mediating DNA transfer (17). In a previous study, similar T4SS subtypes were detected in Streptococcus agalactiae, Streptococcus pneumonia and Pyogenic streptococcus (5). In addition, our study group first identified the existence of T4SS in $C$. difficile and its association with $C$. difficile virulence (5), suggesting that T4SS may serve as the vital mechanism underlying the secretion of toxins A and B.

In the present study, 37 strains of $C$. difficile from different sources and with different STs were preliminarily screened for VirB4, VirB6 and VirD4 to investigate the distribution profile of T4SS in C. difficile. Of these 37 strains, 25 were positive for toxins $\mathrm{A}$ and $\mathrm{B}$, and the remaining 12 were negative for toxin A and positive for toxin B. MLST identified 7 strain types, including 11 strains with ST37, 10 with ST2, 6 with ST35, 7 with ST3, 1 with ST54, 1 with ST1 and 1 with ST119. Considering the variety of geographic and ST factors, 9 strains of 3 regions and 5 STs were selected for PCR sequencing. The positive rate of T4SS was up to $100 \%$, suggesting heredity disparity in the T4SS of strains with different ST.

There are several limitations to the present study. Firstly, T4SS sequencing analysis of the strains was restricted to the genetic level, and so whether these genes are able to function normally or express functional proteins remains unclear. Therefore, the actual detection rate of T4SS with normal functionality may be lower than reported here. Secondly, only $\mathrm{A}+\mathrm{B}+$ or $\mathrm{A}-\mathrm{B}+$ toxigenic strains were screened in the present study; non-toxigenic strains were not included. Consequently, the exact detection rate of T4SS in $C$. difficile colonies should be further investigated. Thirdly, only $37 C$. difficile strains of 7 STs were investigated. A larger sample-size should be used in future studies to investigate the distribution profile of T4SS on a wider scale.

In conclusion, the detection rate of VirB4, VirB6 and VirD4 is equally $100 \%$ in T4SS, and strains with identical STs possess similar SNP loci. The results of the present study provide a basis for subsequent identification of T4SS distribution, epidemiological investigations, polymorphism analyses and investigations into the association between T4SS, cytotoxicity and enterotoxication in $C$. difficile.

\section{Acknowledgements}

The present study was supported by the National Natural Science Foundation (grant no. 81301402).

\section{References}

1. Bauer MP, Notermans DW, van Benthem BH, Brazier JS Wilcox MH, Rupnik M, Monnet DL, van Dissel JT and Kuijper EJ; ECDIS Study Group: Clostridium difficile infection in Europe: A hospital-based survey. The Lancet 377: 63-73, 2011.

2. Kuijper EJ, Coignard B and Tüll P; ESCMID Study Group for Clostridium difficile; EU Member States; European Centre for Disease Prevention and Control: Emergence of Clostridium difficile-associated disease in North America and Europe. Clin Microbiol Infect 12 (Suppl 6): S2-S18, 2006.

3. Huang H, Wu S, Wang M, Zhang Y, Fang H, Palmgren AC, Weintraub A and Nord CE: Clostridium difficile infections in a Shanghai hospital: Antimicrobial resistance, toxin profiles and ribotypes. Int J Antimicrob Agents 33: 339-342, 2009.

4. Wilkins TD and Lyerly DM: Clostridium difficile testing: After 20 years, still challenging. J Clin Microbiol 41: 531-534, 2003.

5. Zhang W, Rong C, Chen C and Gao GF: Type-IVC Secretion system: A novel subclass of type IV secretion system (T4SS) common existing in gram-positive genus Streptococcus. Plos One 7: e46390, 2012.

6. Rupnik M: How to detect Clostridium difficile variant strains in a routine laboratory. Clin Microbiol Infect 7: 417-420, 2001

7. He M, Sebaihia M, Lawley TD, Stabler RA, Dawson LF, Martin MJ, Holt KE, Seth-Smith HM, Quail MA, Rance R, et al: Evolutionary dynamics of Clostridium difficile over short and long time scales. Proc Natl Acad Sci USA 107: 7527-7532, 2010.

8. Janvilisri T, Scaria J, Thompson AD, Nicholson A, Limbago BM, Arroyo LG, Songer JG, Gröhn YT and Chang YF: Microarray identification of Clostridium difficile core components and divergent regions associated with host origin. J Bacteriol 191: 3881-3891, 2009.

9. Yan Q, Zhang J, Chen C, Zhou H, Du P, Cui Z, Cen R, Liu L, Li W, Cao B, et al: Multilocus sequence typing (MLST) analysis of 104 Clostridium difficile strains from China. Epidemiol Infect 4: 195-199, 2013.

10. Lemme L, Halluin A, Pestel-Caron M, Lemeland JF and Pons JL: Multilocus sequence typing analysis of human and animal Clostridium difficile isolates of various toxigenic types. J Clin Microbiol 42: 2609-2617, 2004.

11. Kato H, Kato N, Watanabe K, Iwai N, Nakamura H, Yamamoto T, Suzuki K, Kim SM, Chong Y and Wasito EB: Identification of toxin A-negative, toxin B-positive Clostridium difficile by PCR J Clin Microbiol 36: 2178-2182, 1998.

12. Griffiths D, Fawley W, Kachrimanidou M, Bowden R, Crook DW, Fung R, Golubchik T, Harding RM, Jeffery KJ, Jolley KA, et al: Multilocus sequence typing of Clostridium difficile. J ClinMicrobiol 48: 770-778, 2010.

13. Cheng Y, Du P, Chen C, Yan S, Jia H, Wang J, Yan Q, Feng H and Lu J: Toxin A-negative, toxin B-positive Clostridium difficile infection diagnosed by polymerase chain reaction. Infect Control Hosp Epidemiol 32: 520-522, 2011.

14. Govind R and Dupuy B: Secretion of Clostridium difficile toxins $\mathrm{A}$ and $\mathrm{B}$ requires the holin-like protein TcdE. PLoS Pathog 8: e1002727, 2012.

15. Olling A, Seehase S, Minton NP, Tatge H, Schröter S, Kohlscheen S, Pich A, Just I and Gerhard R: Release of TcdA and TcdB from Clostridium difficile cdi 630 is not affected by functional inactivation of the tcdE gene. Microb Pathog 52: 92-100, 2012.

16. Brouwer MS, Roberts AP, Hussain H, Williams RJ, Allan E and Mullany P: Horizontal gene transfer converts non-toxigenic Clostridium difficile strains into toxin producers. Nat Commun 4: 2061, 2013.

17. Segal G, Feldman M and Zusman T: The Icm/Dot type-IV secretion systems of Legionella pneumophila and Coxiella burnetii. FEMS Microbiol Rev 29: 65-81, 2005.

18. Ninio S and Roy CR: Effector proteins translocated by Legionella pneumophila: Strength in numbers. Trends Microbiol 15: 372-380, 2007.

19. Wang P, Xiong Y, Lan R, Ye C, Wang H, Ren J, Jing H, Wang Y, Zhou Z, Cui Z, et al: pO157_Sal, a novel conjugative plasmid detected in outbreak isolates of escherichia coli O157:H7. J Clin Microbiol 49: 1594-1597, 2011.

20. Saenz HL, Engel P, Stoeckli MC, Lanz C, Raddatz G, Vayssier-Taussat M, Birtles R, Schuster SC and Dehio C: Genomic analysis of Bartonella identifies type IV secretion systems as host adaptability factors. Nat Genet 39: 1469-1476, 2007. 